\title{
Uso de tecnologia da informação na agricultura familiar: Planilha para gestão de insumos
}

\author{
Elaine Parra Affonso \\ Cristina Toyoko Hashimoto \\ Universidade Estadual Paulista - Unesp/Marília, Brasil \\ Ricardo César Gonçalves Sant'Ana \\ Universidade Estadual Paulista - Unesp/Tupã, Brasil
}

\section{REVIEW}

\begin{abstract}
Resumo
Objetivo. Demonstrar como a Tecnologia da Informação, por meio de planilhas eletrônicas, podem otimizar a gestão de propriedades rurais, especificamente no setor da agricultura familiar.

Método. Foi realizada uma revisão de literatura sobre o possível uso das Tecnologias da Informação no contexto da agricultura familiar e, análise, por meio de referencial teórico proposto pela Informática Comunitária, de ações oferecidas e efetuadas pelo projeto Competências Digitais para Agricultura Familiar - CoDAF, em especial a planilha "Controle de Estoque de Insumos", que foi estruturada com base nas informações obtidas a partir da interação com produtores rurais, assim, pontuando as necessidades destes em relação a gestão da propriedade rural.

Resultados. Como resultado destas ações, é apresentada a descrição da planilha de "Controle de Estoques de Insumos" e explicitado como a Tecnologia da Informação pode contribuir para minimizar desperdícios no contexto do controle de estoque, proporcionando, assim, a minimização dos custos e aumento na eficiência no processo.

Conclusões. Embora o produtor rural encontre barreiras no acesso às tecnologias mais avançadas e softwares específicos, o uso de planilhas apresenta-se como uma opção viável, pois, principalmente por meio de versões open source tornou-se acessível e pode contribuir para o aprimoramento das atividades rurais, principalmente para o agricultor familiar, contribuindo para redução da assimetria informacional.
\end{abstract}

Palavras-chave

Agricultura Familiar; Tecnologia da Informação; Planilhas; Projetos de Extensão; Informática Comunitária

Information Technology in family agriculture: Spreadsheets for the management of inputs

Abstract

Objective. To demonstrate how Information Technology through electronic spreadsheets may improve the administration of rural activities on farms, specifically within the context of family agriculture.

Method. The literature on the use of Information Technology within the context of family agriculture was reviewed. Using the theoretical referential proposed by Community Informatics, the activities undertaken by the Digital Skills for Family Agriculture - CoDAF project were analyzed, especially the spreadsheet "Input Stock Control", prepared on the information obtained from the interaction with rural producers. Their needs with regard to farm administration were consequently focused.

Results. The spreadsheet "Input Stock Control" is consequently described and Information Technology's contribution how it minimizes waste within the context of stock control is shown, coupled to lowering of costs and increase in the efficaciousness of the process.

Conclusions. Although the farmer may have several impediments to access more advanced technologies and specific softwares, the use of the spreadsheet is a feasible choice due to its availability, mainly in open source versions, especially for family agriculture, and thus contributing towards the reduction of informational asymmetry.

Keywords

Family agriculture; Information Technology; Spreadsheets; Extension Projects; Community informatics 


\section{Introdução}

O aumento da competitividade no setor do agronegócio tem incentivado os gestores da área a buscar alternativas para se destacarem no mercado, como novos processos de produção e gestão, utilizando as Tecnologias da Informação (TI). Assim, pode-se associar esse contexto a visão de Lévy (1993), que aponta a criação de novas maneiras de pensar e conviver no mundo da informática e que relações entre homens, trabalho e inteligência estão dependendo da evolução desses recursos informacionais.

As TI, segundo Batalha, Buainain e Souza Filho (2004), podem otimizar as atividades do agronegócio, inclusive no setor da agricultura familiar, pois além de facilitar a busca, o acesso, o armazenamento e a disseminação de informações, também servirão como instrumento de comunicação e coordenação entre os participantes deste setor. Essas tecnologias são vistas como um fator de competitividade no setor agrícola e, os aplicativos voltados para a agricultura, tem ganhado a atenção não só de grandes produtores, mas também no segmento da agricultura familiar (ASSAD; PANCETTI, 2009).

A agricultura familiar, segundo o Instituto Brasileiro de Geografica e Estatística - IBGE (2006), representa $84,36 \%$ dos estabelecimentos brasileiros, totalizando 4.366 .267 estabelecimentos e, segundo estudos realizados por Guilhoto et al (2005), 1/3 da tributação da produção agropecuária do agronegócio brasileiro é oriunda da agricultura familiar.

Para a Organização das Nações Unidas para Alimentação e Agricultura ${ }^{1}$ - a FAO² - a agricultura familiar inclui

[...] todas as atividades agrícolas de base familiar e está ligada a diversas áreas do desenvolvimento rural. A agricultura familiar consiste em um meio de organização das produções agrícola, florestal, pesqueira, pastoril e aquícola que são gerenciadas e operadas por uma família e predominantemente dependente de mão-de-obra familiar, tanto de mulheres quanto de homens (FAO, 2014, p. 1).

De acordo com Tafuna'l e Maru (2014) as TI podem contribuir para que produtores rurais possam obter um melhor acesso à informação, tais como, acesso a dados climáticos e informações sobre pragas e doenças. Assim, é possível um melhor planejamento e monitoramento da produção, inclusive otimizando o processo de venda e comercialização de produtos. Os autores afirmam que esses benefícios são resultados da minimização do custo das $\mathrm{TI}$ e o imenso poder de acessibilidade da computação.

Embora, haja um grande número de $\mathrm{TI}$, direcionadas à agricultura, muitas vezes a sua disponibilidade e acessibilidade ainda está muito dispersa e não se apresentam integradas de maneira a ajudar o agricultor familiar a aprimorar as suas práticas agrícolas.

Para Deponti (2014) existe um descompasso entre os vários softwares de gestão e a pouca aderência por parte dos produtores, visto que existe uma desconexão das aplicações com as necessidades e habilidades deste público.

O uso das TI por agricultores familiares ainda é limitado, pois é preciso considerar um cenário em que o acesso a estas tecnologias, inclusive a internet, é escassa ou inexistente. No entanto, alguns produtores já utilizam internet e softwares aplicativos, mesmo que estes não sejam específicos e complexos, como, o uso de "planilhas eletrônicas" para apoiar as tarefas cotidianas (ASSAD; PANCETTI, 2009).

Todavia, a deficiência no acesso e recuperação da informação adequada, faz surgir ações e projetos que buscam alternativas para melhorar a disponibilização da informação para o produtor rural. A disponibilização destas informações se tornam relevantes ao permitir que os produtores organizem suas atividades, melhorem sua renda e minimizem os seus custos de produção.

Este artigo tem o objetivo de demonstrar como ações desenvolvidas com base em uma visão proposta pela Informática Comunitária (community informatic) podem ampliar as possibilidades de uso de planilhas eletrônicas na gestão das propriedades rurais. Como resultado dessas ações, é realizada a descrição da planilha de "Controle de Estoques de Insumos". Este trabalho também evidencia o posicionamento das TI na agricultura familiar e relata práticas de projeto de extensão voltados a este público.

\section{Agricultura familiar e informação}

Ao longo do tempo a agricultura tem se desenvolvido tanto nos métodos de produção, como nos processos de comercialização, que por meio de inovações tecnológicas, possibilitou a criação de mecanismos de junção das TI com elementos da agricultura, originando ferramentas agrícolas avançadas e softwares voltados para a 
agricultura. No Brasil, o agronegócio tem um papel importante para a economia do país e, neste setor agrícola, a agricultura familiar representa um segmento importante do agronegócio brasileiro, não só pela importância social, mas pela produção que é destinada ao consumo nacional (GUILHOTO et al, 2005).

Para Scheneider e Niederle (2010), antes dos anos 90, a expressão agricultura familiar era pouco utilizada, e os termos para representar essa categoria social era pequeno produtor, produtor de baixa renda e produtor de subsistência, entretanto, a partir das lutas de movimentos sindicais e criação de políticas públicas, as diversas denominações foram cedendo lugar para o termo agricultura familiar.

De acordo com Harande (2009) o desenvolvimento neste setor só poderá ser eficaz se os produtores rurais possuírem acesso à informação relevante e diversificada para as suas atividades, visto que, "é exatamente a capacidade de se obter acesso à informação e de transformá-la em conhecimento que precisa ser expandida também para o espaço rural" (BERNARDES; TORRES, 2010, p 6.). Esta informação, segundo Capurro e Hjorland (2003) torna-se necessária para o desenvolvimento econômico juntamente com o capital, o trabalho e a matéria-prima, e deve ser definida em relação à necessidade do público alvo servido pelos especialistas em informação.

A informação é matéria-prima para o desenvolvimento, tanto para os moradores urbanos e rurais. Prosperidade, progresso e desenvolvimento de qualquer nação dependerá da capacidade do país para adquirir, produzir, acessar e usar as informações pertinentes [...].O acesso à informação também é crucial para permitir que as pessoas conheçam os seus direitos a benefícios sociais e fontes de apoio para superar a exclusão social (HARANDE, 2009, p.1, tradução nossa ${ }^{3}$ ).

Assim, pode-se atribuir a Ciência da Informação o papel de atender a demanda pela busca de informação, uma vez que cabe a Ciência da Informação investigar o comportamento da informação, bem como o fluxo e o acesso a esta (BORKO, 1968).

Com base nestas considerações sobre agricultura familiar e informação, emerge a necessidade de disponibilizar aplicações eficientes e acessíveis para a gestão dos pequenos estabelecimentos rurais. Para Castell (1999) a adoção das TI nas diversas situções proporcionam um cenário repleto de oportunidades para construção de ambientes menos assimétricos, pois para o autor, o que caracteriza a tecnologia não é centralizar o conhecimento e a informação, mas sim a sua aplicação, pois pode contribuir para a geração de novos conhecimentos.

[...] a difusão da tecnologia amplifica seu poder de forma infinita, à medida que os usuários apropriam-se dele e a redefinem. As novas tecnologias da informação não são simplesmente ferramentas a serem aplicadas, mas processos a serem desenvolvidos. Usuários e criadores podem tornar-se a mesma coisa (CASTELL, 1999, p.69).

As $\mathrm{TI}$ se tornam uma das principais vias para o acesso à informação e a diminuição da distância entre o meio rural e o restante da sociedade, assim, contribuindo para minimizar assimetria informacional. Para Silveira ${ }^{4}$ (2003) apud Silva (2014), estas tecnologias representam além da ampliação de novos horizontes e expectativas, novas políticas públicas, acesso a dados de estimativas de safras, serviços bancários e, um instrumento de trabalho.

Um exemplo da adoção de TI por agricultores vem do trabalho realizado por Assad e Pancetti (2009), que relata o caso de um produtor rural que não utiliza software específico para administrar seu sítio, todavia, realiza anotações referentes as atividades agrícolas em planilhas eletrônicas.

Dentre as inúmeras vantagens oferecidas pelas TI, pode-se citar as contribuições no apoio ao processo de tomada de decisão pelo produtor rural, visto que alguns produtores têm demonstrado interesse pelas TI como uma forma de alcançar melhores resultados técnicos e financeiros (VELOSO; FERNANDES; BARIONI, 2005).

Assim, a inclusão das TI no meio rural podem facilitar o acesso à informação e ao conhecimento. No entanto, existem muitas barreiras que dificultam o acesso e disseminação destas, como a inexistência de computadores pessoais, o desconhecimento de programas, o baixo grau de instrução dos trabalhadores rurais e a falta de competências e habilidades no manuseio das aplicações e equipamentos (DEPONTI, 2014).

Além das dificuldades encontradas no uso das TI, existe uma falta de compreensão na necessidade de realizar registros das atividades rurais, tais como, controle de custos, estoque e receita, pois o agricultor não compreende a importância do registro destas informações e, quando existem práticas gerenciais, estes procedimentos são muito simples e distante de serem úteis (BATALHA; BUAINAIN; SOUZA FILHO, 2005). 
Deponti (2014) também corrobora com a ideia de que o produtor não tem percepção da necessidade e da utilidade de realizar anotações para contribuir na gestão da sua propriedade e que existe uma disparidade entre o uso e apropriação das tecnologias, embora muitos produtores tem acesso ao computador, isso não garante que eles compreendam a sua utilização.

As TI podem contribuir para aumentar a divulgação de informações e compartilhar conhecimentos, contudo, os autores Meena e Singh (2013) enfatizam que é necessário não apenas melhorar acessibilidade das TI para o produtor rural, mas também de melhorar a sua relevância no desenvolvimento local.

A realização de práticas de gestão alinhada à utilização de TI podem proporcionar ao agricultor dados e informações importantes para o processo de tomada de decisão gerencial e maior eficiência no processo produtivo e financeiro (HAMADA; MOREIRA; SANT'ANA, 2014).

Segundo Deponti (2014), é preciso reconhecer que pouco tem sido feito em relação ao desenvolvimento de técnicas de gestão que levam em conta as particularidades da agricultura familiar, pois a maioria dos softwares voltados para a gestão das atividades rurais, ofertadas pelo mercado, necessitam de competências para que possam ser utilizadas

Batalha, Buainain e Souza Filho (2004) destacam que o uso das TI para a gestão na agricultura familiar são fundamentais para competitividade e que fazem parte do conhecimento e das técnicas necessárias para 0 sucesso do empreendimento. Todavia, Deponti (2014) afirma que um desafio no uso das TI na gestão rural é que a maior parte dos agricultores apresentam baixa escolaridade e muitas vezes os seus sucessores, que vão gerir a propriedade param de estudar, assim, dificultando o desempenho da produtividade agrícola e o acesso e uso de novas TI.

A ideia de proporcionar a diminuição da assimetria informacional entre agricultores pode ser possível por meio de projetos de extensão, do oferecimento de cursos e do uso das TI. Segundo Sant'Ana (2013) ao explicitar as vantagens do uso da TI e proporcionar o seu entedimento, torna-se possível minimizar esta assimetrira informacional e tornar o uso desta mais atrativa para toda sociedade.

De acordo com Neves (2002), a extensão é entendida como uma prática acadêmica que interliga as atividades de ensino e de pesquisa da universidade com as necessidades da sociedade, permitindo a formação do profissional-cidadão, de forma a permitir a constante busca do equilíbrio entre as demandas socialmente exigidas e as inovações que surgem na universidade.

Para Freitas e Schoab (2013) o papel da universidade não deve se restringir ao ensino e aprendizagem científica, mas deve também estar voltada a objetivos sociais, por meio de soluções que atendam as principais necessidades da sociedade. Logo, Jorge e Azevedo (2014) acreditam que por meio dessas práticas é possível transformar o contexto social no qual seus participantes estão inseridos.

Assim, o caminho não é unilateral da universidade para a sociedade, mas há a preocupação em auscultar as expectativas produzidas pela sociedade, bem como em valorizar o contexto em que as atividades se inserem, na busca de uma relação de reciprocidade, mutuamente transformadora, em que o saber científico possa se associar ao saber popular (JEZINE, 2004).

Como ressalta o artigo 43 da lei no 9.394, que estabelece as diretrizes e bases da educação nacional: "A educação superior tem por finalidade promover a extensão, aberta à participação da população, visando à difusão das conquistas e benefícios resultantes da criação cultural e da pesquisa científica e tecnológica geradas na instituição" (BRASIL, 1996).

Segundo Dagnino (2004), a universidade muitas vezes enxerga como sua única responsabilidade a capacidade de oferecer conhecimento à sociedade, tornando uma concentração de esforço no lado da oferta e não existe uma preocupação com apropriação deste conhecimento. Para resolver esse problema da sociedade, é necessário que a sociedade dê mais valor a ciência, entretanto, a universidade precisa oferecer mais conhecimento à sociedade e mostrar a esta que a ciência é importante.

Nesse cenário, Gurstein (2007) traz o conceito de Informática Comunitária como sendo a aplicação da TI para facilitar os processos em uma comunidade. Assim, torna-se base para capacitar e habilitar indivíduos no uso da TI, podendo atender as necessidades de uma comunidade, tais como: proporcionar a inclusão digital; aprimorar as atividades diárias e trazer novas oportunidades para melhorar as condições de vida dos indivíduos. O autor considera o estudo e implementação de sistemas de informação como ferramentas de apoio para atingir os 
objetivos da comunidade e que essas aplicações podem promover o desenvolvimento social e econômico das comunidades.

Com o objetivo de atender as necessidades de uma comunidade específica nas deficiências no uso das $\mathrm{TI}$, surgem iniciativas como as do projeto de extensão "Competências Digitais para Agricultura Familiar" - CoDAF da UNESP campus de Tupã - SP.

O CoDAF tem como objetivo oferecer alternativas para que os agricultores, principalmente os agricultores familiares, tenham acesso as informações destinadas a estes, minimizando os aspectos que dificultam esse acesso. Este projeto se demonstra capaz de atuar no desenvolvimento de cursos e oficinas preparatórias, visando desenvolver habilidades para que os agricultores possam ter acesso a informações sobre o setor e 0 mercado e, na divulgação de suas práticas e culturas, de forma que estes possam concorrer em igualdade com produtores de maior porte (CODAF, 2015).

Por meio do portal CoDAF são realizadas a divulgação de cursos e atividades desenvolvidas pelo projeto, e são disponibilizadas informações relacionadas a agricultura, como informações sobre programas governamentais e a respeito da agricultura familiar. O portal também proporciona aos agricultores informações sobre as propriedades rurais e por meio de um cadastro, o próprio agricultor realiza a inserção dos dados da sua propriedade (CODAF, 2015).

O projeto busca alternativas de proporcionar novas oportunidades ao agricultor familiar, como também pontuar suas necessidades. Desta forma, é possível conhecer as demandas e necessidades do público alvo, e assim, criar conhecimento da cultura e das atividades dos sujeitos envolvidos.

Em relação ao oferecimento de cursos, o CoDAF realiza capacitações, como o curso intitulado de "Introdução ao uso de planilhas na gestão de propriedades rurais" que é destinado ao produtor rural, com a finalidade de desenvolver habilidades técnicas para que este possa aprimorar o gerenciamento de suas atividades com o uso das TI. Neste curso, os produtores receberam instruções sobre conceitos iniciais de planilhas, como, manuseio do software, uso de fórmulas e funções, e posteriormente aplicaram os conhecimentos adquiridos na planilha de "Controle de Estoque de Insumos", desenvolvida pelos membros do CoDAF, com o objetivo de minimizar os riscos de perda e ter maior controle sobre a compra de insumos. A planilha está disponível no sítio do $\operatorname{CoDAF}^{5}$ e sempre é alinhada com as sugestões e colaborações dos agricultores durante o curso e ações da Informática Comunitária.

De acordo com Reinaldo Messias, consultor do Sebrae-SP, realizar a gestão do estoque é fundamental para atingir lucro, "quem faz o controle eficiente do estoque frequentemente, [...] tem mais qualidade no serviço prestado ou produto comercializado" (SEBRAE, 2012).

A utilização de instrumentos de gestão pelos produtores rurais são importantes para que estes possam realizar o planejamento de suas atividades. Segundo os estudos realizados por Dorr et al. (2012), mostraram que a maioria dos produtores rurais apenas guardam os recibos de compras e vendas como forma de controle das vendas e do estoque, e a falta de um instrumento de controle prejudica a formação do custo da produção e o preço das vendas dos produtos. Portanto, a realização da gestão do controle de estoques é importante para os processos de tomada de decisão (DORR, et al 2012).

Para Deponti (2014) a inclusão das novas tecnologias informacionais exigem uma construção conjunta do conhecimento, por meio de diálogos e capacitações, assim sendo, os produtores rurais deverão acessar estas tecnologias e utilizá-las no processo de gestão da sua propriedade, como por exemplo, a utilização de planilhas eletrônicas.

Iniciativas como as de Hamada, Moreira e Sant'ana (2014) ao desenvolverem planilhas eletrônicas para cálculo da depreciação de ativos em granjas familiares de postura comercial, demonstraram como a inserção de práticas contábeis alinhadas à utilização das TI podem contribuir para a tomada de decisão gerencial e aprimorar o processo produtivo e eficiente. O desenvolvimento da planilha foi realizada conjuntamente com os gestores, que contribuíram com informações referentes ao processo.

Para Hamada, Moreira e Sant'ana (2014) o uso de planilhas está dentre as possibilidades de aplicação das TI nas atividades rurais e, mesmo sendo aplicadas de forma simples, estas podem ser úteis para as atividades gerenciais e está cada vez mais sendo utilizadas pelo produtor rural de pequeno porte, que muitas vezes não possuem um software específico para a gestão de sua propriedade e ainda carecem de competências digitais. 


\section{Metodologia}

Este trabalho foi estruturado em duas etapas: (1) uma revisão de literatura sobre o potencial uso de TI no contexto da agricultura familiar, a fim de compreender como essas tecnologias estão presentes nesse setor e possíveis contribuições para o pequeno produtor rural, e; (2) análise, por meio de referencial teórico proposto pela Informática Comunitária, de ações oferecidas e realizadas pelo projeto CoDAF, em especial pelo caso da planilha "Controle de Estoque de Insumos" que foi elaborada com base em elementos obtidos a partir de interação com produtores rurais, configurando, assim, um processo de identificação e estruturação de necessidades destes em relação a gestão da propriedade rural.

\section{Resultados e discussões}

O agricultor familiar muitas vezes encontra barreiras para utilização das TI, como, não ter condições financeiras para adquirir um software específico ou dificuldades para utilizar a aplicação, assim, faz-se necessário a elaboração de aplicações que sejam mais fáceis à apropriação e utilização.

A aplicação foi estruturada como planilha eletrônica, pois a maioria dos computadores já possuem pacotes de aplicação para escritório instalado, não precisando o produtor realizar instalação de algum software específico. $\mathrm{Na}$ aplicação explicitada neste trabalho, utilizou-se do software aplicativo Microsoft Office Excel. Esta planilha ${ }^{6}$ pode ser baixada gratuitamente do sitio do CoDAF para o computador do agricultor, que precisará apenas de um software que execute planilhas eletrônicas, podendo ser livre ou proprietário.

A aplicação disponibilizada no sítio do CoDAF e que faz parte das atividades do curso "Uso de planilhas para gestão de propriedade rurais" aborda o controle de estoque de insumos, necessidade que foi identificada por meio das atividades da Informática Comunitária, pois muitos produtores ainda realizam o controle e o gerenciamento das suas atividades utilizando apenas o papel.

A aplicação "Controle de Estoque de Insumos" contempla os cadastros de insumos, atividades (cultura), unidades, nota fiscal, saída de insumos, consulta de insumos no estoque e disponibiliza relatórios para os produtores verificarem quais atividades (culturas) fizeram uso de insumos e a movimentação do estoque, com as entradas e saídas.

As planilhas de cadastro de insumos, cadastro de atividades e cadastro de unidades permitem que os dados de entrada sejam definidos pelos próprios produtores, em cada planilha é permitido excluir os registros da tabela, tornando a planilha adaptável a qualquer propriedade rural.

A quantidade de insumos adquiridas pelo produtor são cadastradas na planilha "Cadastro da nota fiscal", que tem o objetivo de armazenar dados relativos à entrada de insumos, tais como: $n^{\circ}$ da nota fiscal; data da compra do insumo; fornecedor; o nome do insumo; unidade; valor unitário; quantidade e valor total, sendo este último o resultado do valor unitário multiplicado pela quantidade.

Com o objetivo de decrementar o estoque de cada insumo, a planilha "Saída de Insumos" permite que a partir do momento que o produtor escolha o insumo que será retirado do estoque, sejam disponibilizados os dados referentes à unidade e em qual cultura será utilizado este insumo, é necessário incluir a data de saída do insumo e a quantidade retirada do estoque.

Após o cadastro da saída do insumo, o agricultor pode visualizar as informações referentes à movimentação do estoque (entradas e saídas do insumo) consultando a planilha "Consulta do Estoque" (Figura 1).

\begin{tabular}{|c|c|c|c|}
\hline C & $\mathrm{D}$ & $\mathrm{E}$ & $\mathrm{F}$ \\
\hline \multicolumn{4}{|c|}{ CONSULTA DO ESTOQUE } \\
\hline INSUMO & QUANTIDADE EM ESTOQUE & QUANTIDADE RETIRADA & SALDO NO ESTOQUE \\
\hline Fertilizante de Uréia & 5 & 2 & 3 \\
\hline \begin{tabular}{|l|} 
Escolha um \\
insumo!
\end{tabular} & & Menu & \\
\hline
\end{tabular}


Por meio da planilha consulta do estoque (Figura 1) é possível que o produtor rural obtenha informações sobre o saldo atual, quantidade inserida e retirada do seu estoque. Na coluna "Quantidade em estoque" é contabilizado, o estoque inicial que o agricultor informou no cadastro do insumo e a quantidade cadastrada pela nota fiscal. Este conjunto de dados é disponibilizado a partir da escolha do insumo que foi cadastrado na nota-fiscal.

Com o objetivo de visualizar as informações da movimentação do estoque, a planilha de "Relatório de Entradas e Saídas por Insumos" disponibiliza a quantidade do estoque inicial, totalização das quantidades inseridas na nota fiscal, quantidade total de entradas e saídas no estoque e o saldo atual, inclusive a descrição de entradas e saídas por datas (Figura 2). Estes dados são recuperados quando o agricultor seleciona o insumo (que já foi previamente cadastrado na nota-fiscal ou no cadastro de insumos).

\begin{tabular}{|c|c|c|c|c|c|c|}
\hline $\mathrm{L}$ & A & B & C & D & $\mathrm{E}$ & $\mathrm{F}$ \\
\hline 2 & \multicolumn{6}{|c|}{ RELATÓRIO DE ENTRADAS E SAÍDAS POR INSUMOS } \\
\hline \multicolumn{7}{|c|}{20} \\
\hline 4 & INSUMO & ESTOQUE INICIAL & $\begin{array}{l}\text { TOTAL DE ENTRADAS } \\
\text { (NOTA FISCAL) }\end{array}$ & $\begin{array}{c}\text { QUANTIDADE NO } \\
\text { ESTOQUE }\end{array}$ & $\begin{array}{c}\text { QUANTIDADE } \\
\text { DE SAÍDAS }\end{array}$ & $\begin{array}{c}\text { SALDO ATUAL NO } \\
\text { ESTOQUE }\end{array}$ \\
\hline 5 & Adubo & 5 & 10 & 15 & 7 & 8 \\
\hline 6 & \multirow[t]{6}{*}{$\begin{array}{l}\text { Lit } \\
\begin{array}{l}\text { Escolha o } \\
\text { Insumo! }\end{array}\end{array}$} & & & & & \\
\hline 8 & & \multicolumn{2}{|c|}{ Entradas por Nota Fiscal } & \multicolumn{2}{|c|}{ Saídas de Insumos } & \multirow{5}{*}{ Menu } \\
\hline 9 & & Data & Entrada & Data & \begin{tabular}{|l} 
Saída \\
\end{tabular} & \\
\hline 10 & & $12 / 02 / 2015$ & 10 Litros & $13 / 02 / 2015$ & 4 Litros & \\
\hline 11 & & & & $13 / 02 / 2015$ & 3 Litros & \\
\hline 12 & & & & & & \\
\hline
\end{tabular}

Figura 2: Modelo de Relatório de Entrada e Saída por Insumos Fonte: CoDAF (2015)

Por meio desta planilha o agricultor consegue de uma forma rápida e clara verificar se determinado produto tem quantidade necessária para ser utilizada ou não, inclusive obtendo conhecimento das datas que ocorrem as entradas e saídas do estoque, com suas respectivas quantidades.

A aplicação permite que o produtor recupere por meio da planilha "Relatório de Atividades e utilização de Insumos" quais insumos foram utilizados em determinada cultura, e as quantidade e datas que ocorreram as retirada do estoque.

Com a utilização destes relatórios e consultas é possível o produtor ter subsídios para planejar antecipadamente o uso de insumos, tomar decisões em relação à compra destes, evitar desvios de insumos e identificar os insumos que não estão sendo mais utilizados.

A informação disponibilizada ao produtor por meio das TI é fundamental para minimizar o desperdício e, portanto, pode proporcionar a diminuição dos custos e o aumento na eficiência do seu processo

\section{Considerações finais}

Diante da crescente oferta de informações por meio das TI, observar-se sua contribuição para que os produtores rurais tenham alternativas que propiciem melhor acesso à informação e façam o uso de ferramentas que permitam transformar a gestão da sua propriedade rural, implicando em otimização de seu processo de produção por meio do ganho de eficiencia no processo de tomada de decisão.

Por meio da oferta de cursos e disponibilização de aplicações, como a planilha "Controle de Estoque de Insumos", é possível despertar nos produtores a percepção sobre os benefícios trazidos pelas TI, motivando-os para busca por capacitação e justificando esforços para que possam fazer uso dessas aplicações.

Embora muitas vezes o produtor rural não tenha acesso às tecnologias mais avançadas e softwares específicos, o uso de planilhas pode ser considerado um recurso viável para este público, em função de versões open source (sem custo) e, principalmente, por seu potencial como ferramenta de organização e tratamento de dados, podendo contribuir para o aprimoramento da gestão nas suas atividades rurais.

Controlar o estoque de insumos é essencial para o produtor rural, assim é possível identificar o que está faltando e evitar o excesso de insumos, permitindo um melhor planejamento na compra e evitando perdas, possibilitando manter o estoque organizado e com insumos suficientes para utilizar na sua produção. 
Este trabalho buscou identificar e descrever, por meio da Informática Comunitária, como o uso de planilhas resultantes de ações de projetos de extensão podem resultar em benefícios diretos para a sociedade, especificamente para o produtor rural

Iniciativas de extensão como as do projeto CoDAF podem ir além de resultados diretos junto aos produtores e proporcionar conhecimentos científicos, possibilitando interligar resultados de pesquisa com necessidades da sociedade, especificamente a agricultura familiar, buscando atingir objetivos sociais e educacionais por meio do equacionamento entre as demandas do público alvo e ações geradas no contexto da universidade.

\section{Referências}

ASSAD, L.; PANCETTI, A. A silenciosa revolução das TICs na agricultura. ComCiência (UNICAMP), Campinas (SP), v. 110, p. x, 2009. Disponível em: <http://comciencia.scielo.br/scielo.php?script=sci arttext\&pid=S151976542009000600005\&lng=pt\&nrm=iso>. Acesso em: $15 \mathrm{fev} .2015$.

BERNARDES, R. M. TORRES, T. Z. Tecnologias Sociais, TICs e Educação: pilares para a construção da Tecnopedia Social Rural - TeSoRu. Anais do Simpósio Brasileiro de Informática na Educação (SBIE), 2010. Disponível em: <http://ainfo.cnptia.embrapa.br/digital/bitstream/item/23825/1/75376-1.pdf> . Acesso em: 12 maio 2015.

BATALHA, M. O.; BUAINAIN, A. M.; SOUZA FILHO, H. M. Tecnologia de gestão e agricultura familiar. Disponível em: $<$ http://www.sober.org.br/palestra/12/020122.pdf>. Acesso em: 28 fev. 2015.

BORKO, H. Information science: what is it? American Documentation, v.19, n.1, p.3-5, Jan. 1968.

BRASIL. Lei no 9.394, de 20 de dezembro de 1996. Estabelece as diretrizes e bases da educação nacional. Diário Oficial da União. Brasília, 1996. Disponível em:<http://www.planalto.gov.br/CCIVIL 03/leis/L9394.htm>. Acesso em: 31 Jan. 2015.

CAPURRO, R.; HJORLAND, B. The Concept of Information. Theorizing Information and Information Use. Annual Review of informatiocn Science and Technology. Ed. Blaise Cronin. v. 37, cap. 8, p.343-411, 2003.

CODAF. Sobre o CoDAF. Disponível em: <http://codaf.tupa.unesp.br/index.php/codaf-o-codaf>. Acesso em: 25 fev. 2015.

DAGNINO, R. P. A tecnologia social e seus desafios. Disponível em:

<http://www.ige.unicamp.br/site/htm/19.php?local=6\&docente=138>.Acesso em: 24 fev. 2015.

DEPONTI, C. M. As "Agruras" da gestão da propriedade rural pela agricultura familiar. REDES - Rev. Des. Regional, Santa Cruz do Sul, v. 19, Ed. especial, p. 9.24, 2014.Disponível em: <http://online.unisc.br/seer/index.php/redes/article/view/5150/3555>. Acesso em: 12 maio 2015.

DORR, A. C.; et al. Utilização de instrumentos de gestão contábil pelos produtores agropecuários. Revista Eletrônica de Contabilidade, Santa Maria, v. 6, n.1, jan./jun./2012. Disponível em:<http://cascavel.cpd.ufsm.br/revistas/ojs2.2.2/index.php/contabilidade/article/view/35/3412 >. Acesso em: 01 mar. 2015.

FOOD AND AGRICULTURE ORGANIZATION. O que é a Agricultura Familiar? Itália, 2014. Disponível em: $<$ <ttp://www.fao.org/family-farming-2014/home/what-is-family-farming/pt>. Acesso em: 03 mar. 2015.

FREITAS, C. C. G.; SCHOAB, V. A universidade e a tecnologia social: análise da aderência. Congresso Internacional de Administração (ADM 2013) - gestão estratégica: criatividade e interatividade. Disponível em: <http://www.admpg.com.br/2013/selecionados.php?ordem01=titulo\&ordem02=autor >. Acesso em: 22 fev. 2015

GUILHOTO, Joaquim J. M. et al . A importância do agronegócio familiar no Brasil. Rev. Econ. Sociol. Rural, Brasília, v. 44, n. 3, p. 355-382, Sept. 2006 . Disponível em: <http://www.scielo.br/scielo.php?script=sci arttext\&pid=S0103$20032006000300002 \& \operatorname{lng}=e n \& n r m=i s o>$. Acesso em: 23 fev. 2015.

GURSTEIN, M. What's is community informatics? (and why does matter)? Polimetrica: Milan, 2007. Disponível em: <http://eprints.rclis.org/10919/1/WHAT IS COMMUNITY INFORMATICS reading.pdf>. Acesso em: 10 mar. 2015.

HAMADA, I. H.; MOREIRA, F. M. SANT'ANA, R. C. G. A Realização de Práticas contábeis em organização rurais de pequeno porte e o papel das TIC como facilitadora: Resultados da utilização de planilhas eletrônicas para cálculo de depreciação de ativos em granjas familiares de postura comercial. Guia Gessulli da avicultura e suinocultura industrial. Edição AI 1237|SI 260, 2014.

HARANDE, Y. I. Information Services for Rural Community Development in Nigeria. Library Philosophy and Practice (ejournal). Paper 271. Disponível em: <http://www.webpages.uidaho.edu/ mbolin/lpp2009.htm>. Acesso em: 23 fev. 2015.

INSTITUTO BRASILEIRO DE GEOGRAFICA E ESTATÍSTICA. Censo agropecuário 2006: Agricultura Familiar. Primeiros resultados. Brasília, 2006. 267 p. ISSN: 0103-6157. Disponível em:

<http://www.ibge.gov.br/home/estatistica/economia/agropecuaria/censoagro/agri familiar 2006/familia cens oagro2006.pdf>. Acesso em: 02 fev. 2014. 
JEZINE, E. As Práticas Curriculares e a Extensão Universitária. CONGRESSO BRASILEIRO DE EXTENSÃO UNIVERSITÁRIA (2ㅇ: 2004: Belo Horizonte). Anais. Belo Horizonte, 2004. Disponível em: $<$ https://www.ufmg.br/congrext/Gestao/Gesta012.pdf >. Acesso em: 24 fev. 2015.

JORGE, L. S.; AZEVEDO, A. B. Tecnologia Social na Universidade Brasileira: O caso da UFRB. Revista Extensão Vol. 6, n.1. Disponível em: <http://www2.ufrb.edu.br/revistaextensao/images/revista/Revista\%20Extensao\%20-\%206\%20Volume.pdf>. Acesso em: 23 Mar. 2015.

LÉVY, P. As Tecnologias da Inteligência: O Futuro do Pensamento na Era da Informática. Tradução de Carlos Irineu da Costa. Rio de Janeiro: Ed. 34, 1993.

MEENA ,H.R.; SINGH Y.P. Importance of information and communication technology tools among livestock farmers: A review. Scientific Journal of Pure and Applied Sciences (2013) 2(2) 57-65. Disponível em: <http://www.sjournals.com/index.php/SJPAS/article/viewFile/466/514 >. Acesso em: 3 Maio 2015.

NEVES, C.E.B. A estrutura do Ensino Superior no Brasil. In: SOARES, M. S. A. (Org.) A Educação Superior no Brasil. Brasília: Coordenação de Aperfeiçoamento de Pessoal de Nível Superior, 2002. Disponível em: <http://unesdoc.unesco.org/images/0013/001393/139317por.pdf>. Acesso em: 04 Fev. 2015.

SANT'ANA, R. C. G.; Ciclo de vida dos dados e a ciência da informação. In: XIV Encontro Nacional de Pesquisa em Ciência da Informação (ENANCIB 2013). Anais. Informação e Interação: ampliando perspectivas para o desenvolvimento humano. Florianópolis, 2013. Disponível em: <http://enancib2013.ufsc.br/index.php/enancib2013/XIVenancib/paper/viewFile/284/319>. Acesso em: 28 fev. 2015.

SEBRAE. Estoque é dinheiro: planeje, controle e melhore a gestão. (2012) Disponível em: $<$ http://www.sebraesp.com.br/index.php/41-noticias/administracao/7096-estoque-e-dinheiro-planeje-e-controle>. Acesso em: 02 mar. 2015

SCHNEIDER, S.; NIEDERLE, P. A. Agricultura familiar e teoria social: a diversidade das formas familiares de produção na agricultura.Savanas: desafios e estratégias para o equilíbrio entre sociedade, agronegócio e recursos naturais. Planaltina, DF: Embrapa Cerrados, p. 989-1014, 2008. Disponível em: <http://simposio.cpac.embrapa.br/simposio/projeto/palestras/capitulo 32.pdf>. Acesso em: 29 Maio 2015.

SILVA, M. G. A apropriação das TICS por extensionistas e agricultores familiares: possibilidades para o desenvolvimento rural. Santa Maria: UFSM, 2014. Tese de Doutorado. Disponível em: <http://cascavel.ufsm.br/tede//tde busca/arquivo.php?codArquivo=5693>. Acesso: 02 Jun. 2015.

TAFUNA'L, Faumuina, MARU, Ajit. ICTs improving family farming. ICT update. Building resilience for family farming. Issue no 78. September 2014. Disponível em: <http://ictupdate.cta.int/Regulars/Guest-editor/ICTs-improving-familyfarming/\%2878\%29/1409243681 >. Acesso em: 02 mar. 2015

TAVARES, M. das G. M. Extensão Universitária: Novo Paradigma de Universidade. Disponível em: <http://www.anped11.ueri.br/19/TAVARES.htm>. Acesso em: 02 mar 2015.

VELOSO, R. F.; FERNANDES, F. B.; BARIONI, L. G. A importância do controle financeiro em um sistema de informações gerenciais numa fazenda familiar. Embrapa Cerrados, 2003. 


\section{Dados dos autores}

\section{Elaine Parra Affonso}

Doutoranda no Programa de Pós-Graduação em Ciência da Informação - UNESP/Marília - SP. Professora na Faculdade de Tecnologia de Presidente Prudente - Fatec - SP. Departamento de Análise e Desenvolvimento de Sistemas.

elaineaffonso@marilia.unesp.br

\section{Cristina Toyoko Hashimoto}

Mestranda no Programa de Pós-Graduação em Ciência da Informação - UNESP/Marília - SP. Graduada em Administração na UNESP/Tupã.

crishashimoto@marilia.unesp.br

\section{Ricardo César Gonçalves Sant'Ana}

Professor Doutor no Programa de Pós-Graduação em Ciência da Informação - UNESP/Marília - SP. Professor Doutor na Universidade Estadual Paulista - UNESP/Tupã - SP. Doutor em Ciência da Informação UNESP/Marília - SP. ricardosantana@marilia.unesp.br

Recebido - Received: 2015-06-17

Aceitado - Accepted: 2015-10-08

\section{Notas}

1 Tradução do idioma inglês de Food and Agriculture Organization of the United Nations (FAO).

2 Food and Agriculture Organization of the United Nations (FAO).

3 Information is raw material for development for both urban and rural dwellers. Prosperity, progress, and development of any nation depend upon the nation's ability to acquire, produce, access, and use pertinent information [...] Access to information is also critical to letting people know their entitlements to welfare benefits and sources of support to overcome social exclusion (HARANDE, 2009, p.1).

4 SILVEIRA, A. C. M. TICs e o combate à exclusão digital no meio rural do Brasil. In: SILVEIRA, A. M. C. da et al. Divulgação cientílifca e tecnologias de informação e comunicação. Santa Maria: UFSM-FACOS, 2003.

5 http://codaf.tupa.unesp.br/codaf-pagina-principal

6 Disponível em http://codaf.tupa.unesp.br/trabalhos/aplicacoes/592-planilha-para-auxiliar-a-gestao-de-insumosem-propriedades-rurais

\section{(cc) $\mathrm{EY}$}

This work is licensed under a Creative Commons Attribution 4.0

United States License.

\section{ULLS D-Sorke}

This journal is published by the University Library System of the University of Pittsburgh as part of its D-Scribe Digital Publishing Program and is cosponsored by the University of Pittsburgh Press. 